\title{
PENGARUH RELIGIUSITAS, PENGARUH SOSIAL DAN DUKUNGAN PEMERINTAH TERHADAP MINAT MENABUNG DI BANK SYARIAH MANDIRI - BEKASI
}

\author{
Muhammad Richo Rianto $^{1}$, Tutiek Yoganingsih ${ }^{2}$ \\ Prodi Manajemen, Fakultas Ekonomi dan Bisnis, Universitas Bhayangkara Jakarta Raya ${ }^{1}$ \\ Prodi Akuntansi, Fakultas Ekonomi dan Bisnis, Universitas Bhayangkara Jakarta Raya ${ }^{2}$ \\ richorianto@gmail.com ${ }^{1}$, tutiek.yoganingsih@dsn.ubharajaya.ac.id ${ }^{2}$ \\ Penulis untuk Korespondensi/E-mail: richorianto@gmail.com
}

\begin{abstract}
Abstrak
Penurunan market share bank syariah mandiri dalam 10 tahun terakhir menimbulkan tandatanya faktor yang mempengaruhinya. Penelitian ini merupakan penelitian yang dibangun untuk mempelajari hubungan religiusitas, pengaruh sosial dan dukungan pemerintah terhadap minat menabung di Bank Syariah Mandiri. Penelitian ini mengambil tiga variabel bebas yaitu religiusitas, pengaruh sosial dan dukungan pemerintah serta satu variabel terikat minat menabung. Penelitian ini merupakan penelitian kuantitatif dengan menggunakan teknik wawancara dengan kuesioner. Data yang digunakan dalam penelitian ini adalah data primer dengan sampel adalah nasabah bank syariah mandiri dengan kriteria tertentu. Penelitian ini menggunakan teknik pengambilan sample yaitu purposive sampling. Responden dalam penelitian ini berjumlah 183 responden, dimana 22 responden tidak memenuhi syarat sehingga ada sebanyak 161 responden yang dapat digunakan dalam penelitian ini. Penelitian ini menggunakan Smart PLS 3.3.2 untuk mengolah data dalam menemukan jawaban atas hipotesis. Hasil penelitian ini menyimpulkan bahwa religiusitas dan pengaruh sosial berpengaruh terhadap minat menabung di bank syariah mandiri - Bekasi, namun dukungan pemerintah memberikan hasil yang berbeda dimana dukungan pemerintah tidak berpengaruh terhadap minat menabung di bank syariah mandiri - Bekasi. Penelitian ini fokus kepada faktor internal dan eksternal yang mempengaruhi minat menabung di Bank Syariah Mandiri - Bekasi. Penelitian ini diharapkan akan memberikan gamabaran kepada Bank Syariah Mandiri dalam mempertimbangkan keputusan bisnis dalam meningkagkan kinerja perusahaan.
\end{abstract}

Kata Kunci : Religiusitas, Pengaruh Sosial, Dukungan Pemerintah, Minat Menabung, dan Bank Syariah

\begin{abstract}
The decline in the market share of independent Islamic banks in the last 10 years has indicated that the factors that influence it. This research is a research that was built to study the relationship of religiosity, social influence and government support on interest in saving at Bank Syariah Mandiri. This study took three independent variables, namely religiosity, social influence and government support and one dependent variable on interest in saving. This research is a quantitative study using interview techniques with a questionnaire. The data used in this study are primary data with samples of independent Islamic bank customers with certain criteria. This study uses a sampling technique, namely purposive sampling. Respondents in this study were 183 respondents, of which 22 respondents did not meet the requirements so that there were 161 respondents who could be used in this study. This study uses SmartPLS 3.3.2 to process data to find answers to hypotheses. The results of this study conclude that religiosity and social influence affect the interest in saving at the Mandiri Islamic bank - Bekasi, but government support gives different results where government support does not affect the interest in saving at the Mandiri Islamic bank - Bekasi. This study focuses on internal and external factors that affect the interest in saving
\end{abstract}


at Bank Syariah Mandiri - Bekasi. This research is expected to provide an overview for Bank Syariah Mandiri in considering business decisions in improving company performance.

Keyword : Religiosity, Social Influence, Government Support, Interest in Saving and Islamic Banking

\section{PENDAHULUAN}

Beradaptasi dengan perkembangan teknologi yang pesat dan lingkungan yang dinamis menjadikan jasa keuangan harus dapat menentukan perubahan strategi dalam merespon permintaan pasar, kebaharuan teknologi dan persaingan ( $\mathrm{Wu}$ et al., 2011). Kemajuan teknologi menjadikan kompetisi pada industri jasa keuangan menjadi lebih ketat setelah masuknya banyak perusahaan finansial teknologi (Kementrian Komunikasi dan Informatika, 2018)

Perbankan Syariah merupakan salah satu kompetitor industri jasa keuangan yang menjadi perhitungan saat ini. Pertumbuhan industri syariah dewasa ini menjadikan pola keuangan syariah ikut diminati. Mayoritas penduduk $87,17 \%$ yang beragama Islam menjadikan perbankan syariah memiliki potensi yang lebih baik di masa yang akan datang. Statistik Perbankan Syariah (SPS) (Keuangan, 2018) mencatat bahwa industri perbankan syariah bertumbuh dan berkembang dengan pesat. Namun dalam perkembangan nya perbankan syariah menyimpan banyak permasalahan. Berikut merupakan pertumbuhan perbankan syariah berdasarkan Islamic Finance Outlook 2015 (Holmes \& Damak, 2014) yang memberikan gambaran bahwa pertumbuhan perbankan syariah berkembang dengan lambat dan market share yang rendah.

Menurut direktur perbankan syariah OJK tahun 2015 (Tempo, 2015) ada tujuh isu penting pertumbuhan perbankan syariah yang stagnasi di Indonesia. Faktor yang memperlambat pertumbuhan perbankan syariah antara lain adalah government support, permodalan yang minim, strategi bisnis, produk yang tidak variatif, sumber daya manusia yang rendah, edukasi perbankan syariah yang kurang dan pengawasan perbankan syariah yang minim, (Tempo, 2015)

Market share yang rendah pada perbankan syariah disebabkan karena kurangnya minat manabung pada bank syariah. Berdasarakan banyak literatur minat menabung disebabkan oleh beberapa faktor (Hanudin Amin, Abdul Rahim Abdul Rahman, 2011).
Variabel religious obligation yang di teliti oleh Amin (2011) juga memiliki pengaruh positif terhadap minat menabung. Penelitian ini menghasilkan bahwa terdapat hubungan yang signifikan antara religiusitas dengan minat menabung dan bertransaksi di bank syariah. Dengan kata lain religiusitas dapat mempengaruhi individu untuk memunculkan suatu perilaku yang erat kaitannya dengan hal-hal yang menyangkut hukum islam (syariah).

Variabel social influence menunjukkan pengaruh yang positif antara social influence dengan minat menabung. Hasil ini sejalan dengan penelitian yang dilakukan oleh Amin (2011) yang menunjukkan pengaruh positif antara social influence dengan minat menabung.

Dukungan pemerintah merupakan tindakan pemerintah dalam mempengaruhi perilaku pada sektor rumah tangga, perusahaan dan bisnis internasional. Peranan pemerintah memiliki pengaruh besar terhadap perkembangan produk perbankan syariah. (Hanudin Amin, Abdul Rahim Abdul Rahman, 2011). Dengan adanya dukungan pemerintah akan mempermudah regulasi dalam berjalanan nya bisnis dalam perusahaan, khusus nya perbankan syariah. Beberapa penelitian telah banyak membahas mengenai dukungan pemerintah terhadap minat dan menemukan hasil yang inkonsistensi. (Arwan et al., 2018) (Naury Ayu Pramaishella, n.d.)(Hanudin Amin, Abdul Rahim Abdul Rahman, 2011).

\section{TINJAUAN PUSTAKA}

\section{Religiusitas}

Agama merupakan bentuk aspek religi yang telah dihayati oleh individu di dalam hati. Makna agama digambarkan dalam beberapa aspek-aspek yang harus dipenuhi sebagai petunjuk mengenai bagaimana cara menjalankan hidup dengan benar agar manusia dapat mencapai kebahagiaan, baik di dunia dan di akhirat. Islam adalah suata cara hidup yang dapat membimbing seluruh aspek kehidupan 
manusia dengan aqidah, syariah, dan akhlak (Lujja et al., 2016).

\section{Lingkungan Sosial}

Menurut (Permana \& Parasari, 2019) social influence atau pengaruh sosial dapat diartikan sebagai tingkat dimana seseorang menganggap orang di sekelilingnya sebagai keluarga atau teman yang mengajak seseorang untuk menggunakan atau mencoba sesuatu hal yang baru.

Pengaruh sosial atau social influence biasanya mengacu pada individu mengubah perilaku mereka untuk memenuhi tuntutan lingkungan sosial. Pengaruh sosial dapat dihasilkan dari tindakan, perintah atau permintaan sesuatu. Pengaruh sosial juga berpengaruh terhadap perilaku komunikasi secara individual maupun secara kelompok.(Hanudin Amin, Abdul Rahim Abdul Rahman, 2011)

\section{Dukungan Pemerintah}

Pengertian dukungan adalah segala bentuk informasi verbal ataupun non vetikal yang bersifat saran, bantuan yang nyata maupun tingkah laku diberikan oleh sosialnya. Atau dalam bentuk lain juga bisa berupa kehadiran ataupun segala sesuatu hal yang dapat memberikan keuntungan emosional yang berpengaruh pada tingkah laku penerimaannya.

Pemerintah adalah sebagai alat kelengkapan negara dapat diartikan secara luas dan dalam artis sempit. Pemerintah dalam arti luas mencangkup semua alat kelengkapan negara, yang terjadi dari cabang-cabang kekuasaan eksekutif, legislatif dan yudisial atau alat-alat kelengkapan negara lain yang bertindak untuk dan atas nama negara. Sedangkan Pemerintah juga dapat diartikan dalam arti sempit yaitu pemangku jabatan sebagai pelaksanaan eksekutif atau secara lebih penting, pemerintah sebagai penyelenggara administrasi negara (Manan, 2001)

\section{Kerangka Konseptual}

Gambaran konseptual merupakan design atau gambaran yang dibangun dari kerangka berfikir dari sebuah masalah untuk membentuk suatu kesimpulan pola berfikir (Rianto \& Sulistyowati, 2019). Gambar 1 berikut merupakan kerangka konseptual yang dapat dibangun sebagai berikut:

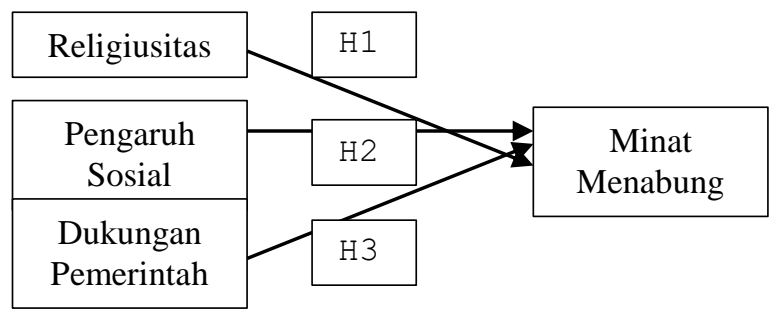

Gambar 1 Kerangka Konseptual

\section{Hipotesis}

Berdasarkan kerangka konseptual yang telah dibangun dalam penelitian ini, maka dapat dibangun beberapa hipotesis sebagai berikut :

\section{Pengaruh Religiusitas terhadap Minat Menabung di Bank Syariah Mandiri}

Berdasarkan definisi agama berperan sebagai pertimbangan dalam mempengaruhi pilihan aktivitas seseorang. Aktivitas dalam islam harus berdasarkan prinsip syariah. Perbankan islam harus mematuhi prinsip, nilai dan tujuan yang berdasarkan prinsip syariah (islam). Kepatuhan seorang muslim salah satunya adalam memilih perbankan yang sesuai dengan prinsip islam ( Bank Syariah). Semakin tinggi kepatuhan seseorang akan ajaran islam maka semakin mungkin seseorang untuk menabung pada perbankan syariah. Berdasarkan argumentasi diatas dapat disumpulkan bahwa: H1. Religiusitas berpengaruh terhadap minat menabung di Bank Syariah

\section{Pengaruh Sosial terhadap Minat Menabung di Bank Syariah Mandiri}

Pengaruh social yang digunakan dalam penelitian ini mengacu pada norma subjektif. Pengaruh sosial berpengaruh positif dengan minat nasabah untuk menggunakan perbankan syariah. Semakin baik pengaruh sosial dalam suatu lingkungan keluarga dan masyarakat.(Hanudin Amin, Abdul Rahim Abdul Rahman, 2011) Semakin besar kemungkinan nasabah menggunakan perbankan syariah.

Berdasarkan argumentasi diatas dapat disimpulkan sebuah hipotesis: H2. Pengaruh social berpengaruh terhadap minat menggunakan Bank Syariah Mandiri di Bekasi

\section{Pengaruh Dukungan Pemerintah terhadap Minat Menabung di Bank Syariah Mandiri}

Dukungan pemerintah berpengaruh positif terhadap niat nasabah menggunakan perbankan 
syariah. Semakin kuat dukungan pemerintah, semakin besar kemungkinannya bahwa pembiayaan perbankan syariah akan digunakan. pernyataan dari (Saiful Azhar, 2005) bahwa pemerintah memiliki pengaruh kuat pada permintaan produk perbankan syariah. Dengan dukungan pemerintah maka akan memperkuat minat nasabah menggunakan perbakan syariah.

Berdasarkan argumentasi diatas dapat ditarik sebuah hipotesis: H3. Dukungan pemerintah berpengaruh terhadap minat menggunakan Bank Syariah Mandiri.

\section{METODE PENELITIAN}

\section{Rancangan Penelitian}

Desain penelitian adalah pedoman atau prosedur serta teknik dalam perencanaan penelitian yang berguna sebagai panduan untuk membangun strategi yang menghasilkan model penelitian (Sujarweni, 2018). Desain penelitian ini menggunakan pendekatan penelitian kuantitatif. Penelitian Kuantitatif adalah jenis penelitian yang menghasilkan sebuah penemuan yang dapat dicapai dengan menggunakan prosedur - prosedur statistik atau cara - cara lain dari pengukuran (Sujarweni, 2018)

\section{Definisi Operasional Variabel}

Penelitian ini mengadopsi dari penelitian yang dilakukan oleh (Hanudin Amin, Abdul Rahim Abdul Rahman, 2011). Variabel religiusitas diadopsi dari penelitian (Hanudin Amin, Abdul Rahim Abdul Rahman, 2011) dengan 5 pernyataan. Sedangkan variabel pengaruh sosial diadopsi dari penelitian (Taib et al., 2008) dengan 5 pernyataan. Variabel dukungan pemerintah diadopsi dari penelitian (Hanudin Amin, Abdul Rahim Abdul Rahman, 2011) dengan 5 pernyataan dan minat menabung diadopsi dari penelitian (Hanudin Amin, Abdul Rahim Abdul Rahman, 2011) dengan 6 pernyataan. Penelitian ini menggunakan Teknik wawancara dengan skala likert 1-5 dengan urutan $1=$ sangat tidak setuju, $2=$ tidak setuju, $3=$ Netral, $4=$ setuju, $5=$ sangat setuju (Mohammad, 2019)

\section{Populasi dan Sampel}

Populasi dalam penelitian ini adalah pengguna bank syariah mandiri di Kota Bekasi. Namun karena tidak diketahui nya jumlah populasi yang akurat dari pengguna bank syariah mandiri di kota Bekasi maka peneliti mengadopsi penelitian dari (Joseph F. Hair Jr. William C. Black \& Anderson, 2014) dimana jumlah indikator dikali (X) 5 sampai dengan 10. Berdasarkan argumentasi ini jumlah minimal sampel dalam penelitian ini adalah $(21 \times 5=105)$.

\section{Teknik Pengambilan Sampel}

Penelitian ini menggunakan teknik non probability sampling dengan memilih purposive sampling yaitu pemilihan sampel berdasarkan kriteria tertentu. Adapun kriteria sampel dalam penelitian ini adalah:

1. Responden sudah memiliki tabungan Bank Syariah Mandiri

2. Responden sudah menjadi nasabah minimal 2 tahun

3. Responden tinggal di wilayah Bekasi

Penelitian ini dilakukan selama 3 bulan dengan teknik wawancara dilakukan dengan menyebarkan kuesioner. Selama 3 bulan data yang berhasil dikumpulkan adalah 183 responden, dimana ada sebanyak 22 responden yang tidak memenuhi syarat sehingga ada sebanyak 161 responden yang dapat digunakan dalam penelitian ini.

\section{Metode Analisis}

Metode analisis data dalam penelitian ini menggunakan data primer dan nasabah bank syariah sebagai unit analisis. Penelitian ini akan menguji kelayakan instrument penelitian dengan menguji validitas dan reliabilitas (uji Outer Model). Tahapan berikut nya adalah menguji hipotesis dalam penelitian (uji Inner model). Alat statistik dalam penelitian ini menggunakan Smartpls.3.3.2

\section{HASIL DAN PEMBAHASAN}

Berdasarkan hasil penelitian yang dilakukan dapat disimpulkan bahwa :

\section{Hasil Uji Instrumen Penelitian (Outer Model)}

Uji instrument penelitian dibagi menjadi 2 pengujian, yaitu validitas dan reliabilitas

\section{Validitas}

Validitas dalam penelitian ini diuji dengan menggunakan Smartpls 3.3.2, Menurut (Beckett et al., 2017) validitas dapat diuji dengan melihat nilai "outer loading" $>0,6$ 


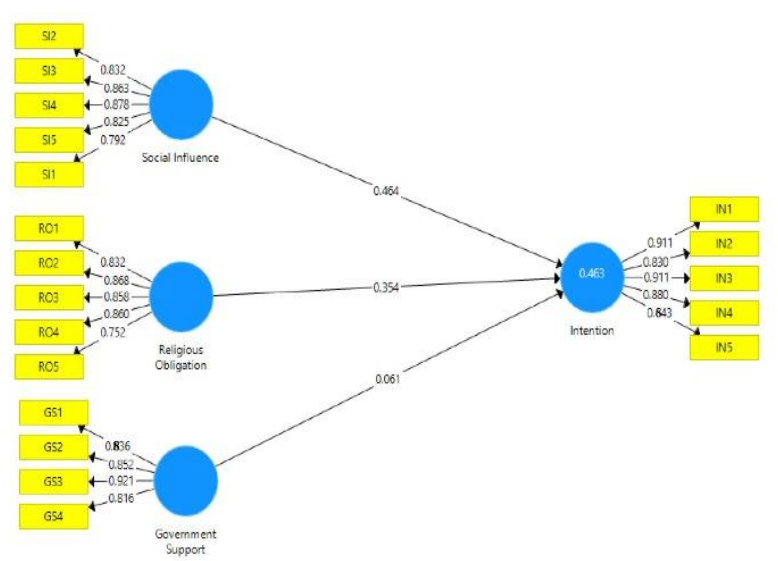

Gambar 2 Validitas Data

Sumber : Data diolah, 2020

Berdasarkan nilai outer loading diatas pernyataan no.5 dukungan pemerintah harus dieleminasi karena tidak memenuhi syarat.

\section{Reliabilitas dan AVE}

Tabel 1 Reliabilitas dan AVE

\begin{tabular}{|l|r|r|r|r|}
\hline & $\begin{array}{l}\text { Cronbach's } \\
\text { Alpha }\end{array}$ & rho_A & $\begin{array}{l}\text { Composite } \\
\text { Reliability }\end{array}$ & (AVE) \\
\hline GS & $\mathbf{0 , 8 7 8}$ & $\mathbf{0 , 8 7 9}$ & $\mathbf{0 , 8 8 5}$ & $\mathbf{0 , 6 6 1}$ \\
\hline IN & $\mathbf{0 , 8 9 2}$ & $\mathbf{0 , 8 9 5}$ & $\mathbf{0 , 9 2 3}$ & $\mathbf{0 , 7 0 8}$ \\
\hline RO & $\mathbf{0 , 8 9 1}$ & $\mathbf{0 , 8 9 7}$ & $\mathbf{0 , 9 2 0}$ & $\mathbf{0 , 6 9 7}$ \\
\hline SI & $\mathbf{0 , 8 9 4}$ & $\mathbf{0 , 9 0 0}$ & $\mathbf{0 , 9 2 2}$ & $\mathbf{0 , 7 0 3}$ \\
\hline
\end{tabular}

Sumber : Data diolah, 2020

Reliabilitas merupakan ukuran kuesioner / item pernyataan yang memenuhi kriteria konsisten yang artinya pernyataan ini dapat memiliki hasil yang konsisten apabila di gunkan untuk mengukur di tempat dan waktu yang berbeda (Sujarweni, 2018).

Menurut(Ghozali, 2016) nilai reliabilitas yang baik jika Cronbach's Alpha bernilai $>0,7$. Berdasarkan table diatas nilai dukungan pemerintah 0,878 , minat menabung 0,892 , religiusitas 0,891 dan pengaruh social 0,894 , yang artinya semua nilai tersebut diatas batas yang ditentukan sebesar 0,7.

\section{Uji Hipotesis Penelitian (Inner Model)}

Pengujian inner model adalah pengujian yang dilakukan untuk membuktikan hipotesis yang dibangun.

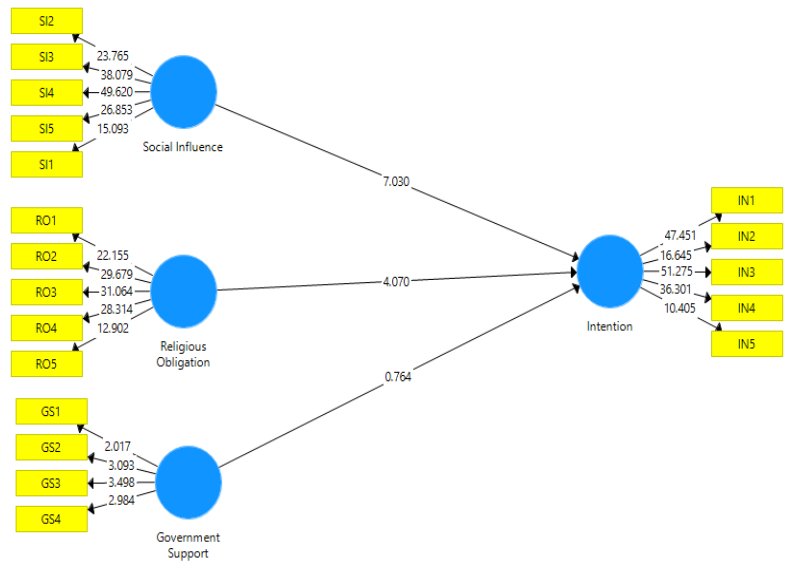

Gambar 3 Uji Hipotesis

Sumber : Data diolah, 2020

Berdasarkan hasil uji hipotesis diatas dapat disimpulkan bahwa:

\begin{tabular}{|c|c|c|c|c|c|}
\hline & \multicolumn{3}{|c|}{ Oirginal Sal Sample Mllean (M) STDEVI } & s(OST) & \\
\hline Covernment Support $\Rightarrow$ Intention & 0,066 & 0,055 & 0,080 & 0,764 & $0,455^{5}$ \\
\hline Religious Sobligation s I Intention & 0,354 & 0,348 & 0,087 & 4,070 & 0,000 \\
\hline 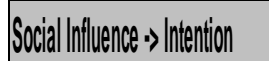 & 0.647 & 0.476 & 0,006 & 7,020 & 0,000 \\
\hline
\end{tabular}

Sumber : Data diolah, 2020

1. Pengaruh religiusitas terhadap minat menabung di Bank Syariah Mandiri, dimana nilai P-value sebesar $0,000<0,05$ sehingga dapat di simpulkan bahwa religiusitas berpengaruh terhadap minat menabung di Bank Syariah Mandiri - Bekasi.

2. Pengaruh sosial terhadap minat menabung di Bank Syariah Mandiri, dimana nilai P-value sebesar $0,000<0,05$ sehingga dapat disimpulkan bahwa pengaruh sosial berpengaruh terhadap minat menabung di Bank Syariah Mandiri Bekasi.

3. Pengaruh dukungan pemerintah terhadap minat menabung di Bank Syariah Mandiri dimana nilai P-value adalah 0,445>0,05 sehingga dukungan pemerintah tidak berpengaruh terhadap minat menabung di Bank Syariah Mandiri - Bekasi.

\section{Pembahasan}

Berdasarkan hasil penelitian diatas maka dapat disimpulkan penjelasan sebagai berikut :

1. Terdapat pengaruh religiusitas terhadap minat menabung di Bank Syariah Mandiri - Bekasi Penelitian ini sejalan dengan penelitian yang 
dilakukan oleh (Hanudin Amin, Abdul Rahim Abdul Rahman, 2011), dimana seseorang yang memiliki tingkat religiusitas yang tinggi maka seseorang akan memilih pilihannya berdasarkan tuntunan agamanya (islam). Hasil ini semakin memperkuat bahwa seseorang dengan tingat ajaran yang baik dan mengikuti nya dengan sungguh sungguh akan memilih perbankan syariah yang sesuai dengan tutunan agamanya yaitu perbankan syariah.

2. Terdapat pengaruh sosial terhadap minat menabung di Bank Syariah Mandiri - Bekasi. Penelitian ini sejalan dengan penelitian (Hanudin Amin, Abdul Rahim Abdul Rahman, 2011) yang meneliti variabel ini di Negara Malaysia. Penelitian ini juga semakin memperkuat argumentasi bahwa manusia adalah mahluk sosial. Pengaruh sosial masyarakat menjadikan behavior seseorang akan terkait satu dan lainnya dalam jangka panjang. Hal ini menjadikan semakin kuatnya pengaruh sosial dalam suatu masyarakat akan memberikan dorongan dalam kelompok sosial bertindak secara bersama sama.

3. Tidak terdapat pengaruh dukungan pemerintah terhadap minat menabung di Bank Syariah Mandiri - Bekasi. Penelitian ini juga sejalan dengan penelitian yang dilakukan oleh (Hanudin Amin, Abdul Rahim Abdul Rahman, 2011) yang menjelaskan bahwa dukungan pemerintah tidak berdampak pada minat menabung di bank syariah. Dukungan pemerintah di Indonesia masih sangat rendah terhadap perbankan khususnya perbankan syariah sehingga kinerja perbankan syariah terbatas karena kurangnya regulasi pemerintah yang mendukung perbankan syariah. Keringanan pajak, akses modal yang rendah, dan edukasi yang minim menjadi peran pemerintah dalam memberikan dukungan pada pengembangan bank syariah di Indonesia.

\section{KESIMPULAN}

Berdasarkan fenomena, inkonsistensi dan hasil temuan dai penelitian ini dapat disimpulkan bahwa Pengaruh religiusitas dan pengaruh sosial memiliki pengaruh terhadap minat menabung di Bank Syariah Mandiri - Bekasi, Namun dukungan pemerintah tidak berpengaruh terhadap minat menabung di Bank Syariah Mandiri - Bekasi.Berdasarkan hasil temuan diatas maka dapat juga disimpulkan bahwa:
1. Religiusitas memiliki nilai P-Value $0,000<0,05$ sehingga religiusitas berpengaruh terhadap minat menabung di bank syariah mandiri - Bekasi. Religiusitas memiliki pengaruh 4,070 dimana pengaruh ini cukup kuat, namun lebih rendah dari pengaruh sosial. H1 diterima

2. Pengaruh sosial terhadap minat menabung di Bank Syariah Mandiri, dimana nilai P-value sebesar $0,000<0,05$ sehingga dapat disimpulkan bahwa pengaruh sosial berpengaruh terhadap minat menabung di Bank Syariah Mandiri Bekasi. Pengaruh sosial memberikan pengaruh terbesar dalam penelitian ini dengan nilai 7.030. H2 Diterima

3. Pengaruh dukungan pemerintah terhadap minat menabung di Bank Syariah Mandiri dimana nilai P-value adalah 0,445>0,05 sehingga dukungan pemerintah tidak berpengaruh terhadap minat menabung di Bank Syariah Mandiri - Bekasi. H3 Ditolak

\section{Implikasi Manajerial}

Berdasarkan hasil temuan penelitian diatas maka penulis merekomendasikan implikasi manajerial bagi perbankan syariah untuk dapat meningkatkan kinerjanya antara lain :

1. Religiusitas berpengaruh terhadap minat menabung sehingga perbankan syariah harus bisa mengedukasi bahwa menabung di bank syariah sesuai dengan perintah agama, perbankan syariah juga dapat mengadakan event - event yang bertujuan untuk mengedukasi pentingnya berbank syariah karena sesuai dengan prinsip islam.

2. Pengaruh sosial berpengaruh terhadap minat menabung sehingga perbankan syariah dapat berkolaborasi dengan komunitas, pengajian, lembaga islam untuk membangun ekosistem islam. Ekosistem islam yang dibangun tidak hanya berlandaskan ekonomi syariah namun dapat mencakup hal yang lebih luas.

3. Dukungan pemerintah tidak berpengaruh terhadap minat menabung. Sehingga perbankan syariah harus dapat membangun komunikasi yang baik dengan pemerintah. Hal ini dapat menjadi keunggulan kompetitif bagi Indonesia dengan membangun perbankan syariah. Jumlah muslim Indonesia yang terbesar di dunia diharapkan menjadi sumber daya yang tidak dapat ditiru oleh negara lainnya. 


\section{Saran}

Penelitian ini belum sempurna dan membutuhkan dukungan dan masukkan dari peneliti lainnya. Oleh karena itu dalam penelitian berikut nya dapat menambahkan variabel lain seperti, sikap dan bagi hasil sebagai variabel bebas (independent) serta dapat menjangkau objek yang lebih luas.

\section{DAFTAR PUSTAKA}

Arwan, A., Kholid, M., Aniesa, M., \& Bafadhal, S. (2018). Pengaruh Kebijakan Pemerintah Terhadap Tingkat Kewirausahaan Di Indonesia (Studi pada Program Kredit Usaha Rakyat Periode Tahun 2008-2014). Jurnal Administrasi Bisnis (JAB)|Vol, 60(3), 10-17.

Beckett, C., Eriksson, L., Johansson, E., \& Wikström, C. (2017). Multivariate Data Analysis (MVDA). In Pharmaceutical Quality by Design: A Practical Approach (Seventh Ed). United States of America: British Library Cataloguing.https://doi.org/10.1002/97811188 95238.ch8

Ghozali, I. (2016). Prosedur Aplikasi Analisis Multivariete Program SPSS.

Hanudin Amin, Abdul Rahim Abdul Rahman, S. L. S. J. and A. M. C. H. (2011). Determinants of customers 'intention to use Islamic personal financing The case of Malaysian Islamic banks.https://doi.org/10.1108/17590811111129 490

Holmes, Z., \& Damak, M. (2014). Islamic Finance Outlook 2015. September 2014.

Joseph F. Hair Jr. William C. Black, \& Anderson, B. J. B. R. E. (2014). Multivariate Data Analysis Seventh Edition.

Kementrian Komunikasi dan Informatika. (2018). Siaran Pers No. 53/HM/KOMINFO/02/2018. siaran pers no. 53/HM/KOMINFO/02/2018, 1. https://kominfo.go.id/index.php/content/detail/ 12640/siaran-pers-no-53hmkominfo022018tentang-jumlah-pengguna-internet-2017meningkat-kominfo-terus-lakukan-percepatanpembangunan-broadband/0/siaran_pers

Keuangan, O. J. (2018). Statistik Perbankan Indonesia.3.https://www.ojk.go.id/id/kanal/per bankan/data-dan-statistik/statistik-perbankanindonesia/Pages/Statistik-PerbankanIndonesia---November-2018.aspx

Lujja, S., Omar Mohammad, M., \& Hassan, R.
(2016). Modelling public behavioral intention to adopt Islamic banking in Uganda: The theory of reasoned action. International Journal of Islamic and Middle Eastern Finance and Management, 9(4), 583-600. https://doi.org/10.1108/IMEFM-08-2015-0092

Manan, B. (2001). Menyongsong Fajar Otonomi Daerah.

Mohammad, H. I. (2019). Mediating effect of organizational learning and moderating role of environmental dynamism on the relationship between strategic change and firm performance. Journal of Strategy and Management, 12(2), 275-297. https://doi.org/10.1108/JSMA-07-2018-0064

Naury Ayu Pramaishella. (n.d.). Pengaruh Modal, Dukungan Pemerintah, dan Kompetensi Sumber Daya Manusia terhadap Kinerja Usaha Mikro, Kecil dan Menengah. 1-27.

Permana, G. P. L., \& Parasari, A. A. A. I. (2019). Pengaruh Hedonic Motivation, Social Influence, Dan Perceived Enjoyment Terhadap Penggunaan Marketplace Pada Umkm Di Bali: Studi Kasus Pada Hipmi Provinsi Bali. Jurnal Ilmiah Manajemen Dan Bisnis, 4(1), 90. https://doi.org/10.38043/jimb.v4i1.2154

Rianto, M. R., \& Sulistyowati, A. (2019). Analisis Faktor Makro Dan Mikro Ekonomi Terhadap Harga Saham Pada Sektor Perbankan Yang Terdaftar Di Bursa Efek Indonesia ( 20132017 ). 15(2).

Saiful Azhar, R. (2005). Critical Issues on Islamic Banking and Financial Markets. October.

Sujarweni, V. W. (2018). Metodologi Penelitian Bisnis dan Ekonomi Pendekatan Kuantitatif. Pustaka Baru Press.

Taib, F. M., Ramayah, T., \& Abdul Razak, D. (2008). Factors influencing intention to use diminishing partnership home financing. International Journal of Islamic and Middle Eastern Finance and Management, 1(3), 235248.https://doi.org/10.1108/175383908109011 68

Tempo. (2015). Otoritas Jasa Keuangan (OJK) Provinsi Bali (KOMUNIKA). 20.

Wu, Y., Wei, Z., \& Liang, Q. (2011). Top management team diversity and strategic change: The moderating effects of pay imparity and organization slack. Journal of Organizational Change Management, 24(3), 267-281. 
https://doi.org/10.1108/09534811111132686 